\title{
FENOMENA BAHASA GAUL SEBAGAI KREATIVITAS LINGUISTIK DALAM MEDIA SOSIAL INSTAGRAM PADA ERA MILENIAL
}

\author{
Syafi’ Junadi, Rani Karomatul Laili
}

\author{
IAI Darussalam Blokagung Banyuwangi \\ junaidisyafi@iaida.ac.id \\ Raniellaili03@gmail.com
}

\begin{abstract}
Abstrak
Permasalahan yang dianalisis dalam skripsi fenomena bahasa gaul sebagai kreativitas linguistik dalam media sosial instagram pada era milenial ini sangat banyak. Untuk memperoleh hasil analisis yang lebih linear dan spesifik, masalah yang dikaji dalam penelitian karya ilmiah ini harus dibatasi dalam karakteristik bahasa gaul dalam media sosial Instagram, padanan kosakata dari bahasa gaul dengan bahasa Indonesia dalam media sosial Instagram dan proses pembentukan satuan lingual bahasa gaul dalam media sosial Instagram dan dampak positif serta dampak negatif dari pemakaian bahasa gaul pada era milenial.Metode penelitian yang digunakan dalam penelitian skripsi ini adalah metode penelitian deskriptif kualitatif dengan tehnik kualitatif fenomenologis. Dalam penelitian ini pengumpulan data dan informasi diperoleh melalui informan, yakni dilakukan dengan cara obvervasi atau pengamatan. Hasil data yang diperoleh melalui teknik pengumpulan data kemudian disusun membentuk laporan yang sistematis yakni pemilik akun instagram pada era milenial.
\end{abstract}

Kata Kunci: Bahasa Gaul, Era Milenial, Media Sosial Instagram

\begin{abstract}
The problems analyzed in the thesis of the phenomenon of slang as linguistic creativity in Instagram social media in this millennial era are numerous. To obtain more linear and specific analysis results, the problems studied in this scientific paper study must be limited to the characteristics of the slang on Instagram social media, the equivalent vocabulary of slang with Indonesian on Instagram social media and the process of forming the lingual unit of slang in the media social Instagram and the positive and negative impacts of using slang in the millennial era. The research method used in this thesis research is a qualitative descriptive research method with phenomenological qualitative techniques. In this study, the collection of data and information was obtained through informants, namely by means of observation or observation. The results of the data obtained through data
\end{abstract}


collection techniques are then compiled to form a systematic report, namely Instagram account owners in the millennial era.

KeyWords:Instagram social media, linguistic creativity, millennial era, slang

\section{A. Pendahuluan}

Komponen komunikasi yang cukup penting dalam membentuk sebuah masyarakat adalah bahasa. Bahasa dalam lingkup masyarakat bersifat dinamis, yakni akan selalu mengalami pergerakan serta perubahan sesuai kebudayaan budaya dalam sebuah masyarakat tersebut.

Seiring dengan semakin berkembangnya zaman sekarang, serta canggihnya tekhnologi, pemakaian bahasa di kalangan remaja atau yang biasa disebut generasi milenial juga mengalami perkembangan serta perubahan. Hal ini memicu lahirnya bahasa gaul di kalangan remaja. Grafura memaparkan tentang bahasa gaul bahwa bahasa tersebut menstimulus lahirnya keinginan untuk memakai bahasa gaul yang mempunyai kesan lebih santai dan tidak terlalu kaku pada remaja. Ketidakbakuan tersebut tergambar dengan jelas dalam penggunaan dari segi kosakata, struktur kalimat, maupun dari segi intonasi.

Penggunaan suatu bahasa oleh generasi milenial terlebih itu bahasa gaul memiliki banyak kemenarikan serta keunikan jika kita cermati serta kita gali secara mendalam. Widayanti (2006:2) pernah menjelaskan bahwasanya bahasa yang dipakai oleh kalangan remaja jika itu adalah bahasa gaul akan bisa menciptakan suasana yang menyenangkan dalam keberlangsungan proses interaksi. Hal ini dapat dikarenakan oleh beberapa faktor, di antaranya adalah:

1 Bahasa gaul lahir dan sering digunakan oleh kalangan remaja dan bahasa gaul masih bersifat asing bagi remaja lain di luar pemakainya; 2 Bahasa gaul berbeda dengan bahasa sandi yang digunakan oleh suatu instansi atau organisasi tertentu;

3 Bahasa gaul memiliki keunikan tersendiri dikarenakan memiliki perbedaan dengan bahasa sehari-hari pada umumnya; 
4 Bahasa gaul mempunyai ciri-ciri kerahasiaan tersendiri bagi kalangan remaja di luar pemakainya;

5 Kosakata dalam bahasa gaul hampir sama dengan bahasa yang sudah kita ketahui, dan biasanya dipakai oleh kalangan remaja pada umumnya.

Bahasa gaul yang biasanya lahir karena sering digunakannya istilahistilah baru oleh pengguna bahasa, telebih oleh generasi milenial kenyataannya dapat mempererat pergaulan juga dapat meningkatkan perbendaharaan kosakata bahasa Indonesia. Hermanto (dalam Mastuti, 2008: 70) menyatakan bahwa bahasa gaul termasuk salah satu dari sekian banyak variasi bahasa yang sering digunakan oleh generasi milenial terutama dari kalangan yang sering kita jumpai pada acara televisi dan kalangan remaja sebagai bahasa yang lebih fleksibel dalam komunikasi sehari-hari untuk menumbuhkan rasa keakraban, keintiman serta kekeluargaan.

Biasanya, kalangan remaja seringkali memakai bahasa spesifik atau bahasa khusus yang biasa disebut dengan istilah bahasa gaul di dalam interaksinya sehari-hari. Baik komunikasi pada dunia nyata maupun komunikasi dalam dunia maya melului sosial media, terlebih sosia media instagram. Piaget menjelaskan bahwa kalangan remaja mulai memasuki usia yang mana tahap perkembangan kognitif mulai berkembang secara sempurna, biasanya tahap ini disebut dengan sebuah tahap formal operasional. Selain itu piaget juga menyampaikan, bahwa tahapan formal operasional ini merupakan tahapan tertinggi dalam perkembangan kognitif manusia.

Bahasa gaul yang dipakai dikalangan remaja semakin kita perhatikan dan mencoba untuk memahami malah justru semakin membuat kita bingung, pusing bahkan heran karena kita juga tidak dapat mengerti serta tidak bisa memahami apa yang mereka bicarakan ataupun tentang apa maksud yang mereka tuliskan pada saat mereka berkomunikasi sesama teman seusianya.

Sebenarnya bahasa yang dipakai dikalangan remaja tersebut adalah bahasa sehari-hari yang juga dipakai oleh masyarakat pada umumnya, perbedaannya, terletak pada kosakata yang dipakai ketika mereka berkomunikasi sudah dimodifikasi misalnya, hurufnya dibolak-balik, terkadang 
juga kata-katanya cukup disingkat, sering menggunakan istilah-istilah baru bahkan terkadang mereka menggunakan istilah asing dan masih beragam cara lain yang mereka gunakan untuk memodifikasinya.

Dari banyaknya bahasa yang mereka ucapkan ini tentunya ada sedikit banyak kosakata yang bisa kita pahami tetapi ada juga sebagian kosakata yang tidak dapat kita pahami makna dan tujuannya. Hal ini bisa membuat bingung sebagian masyarakat yang sama sekali belum mengetahui dan tidak memahami sedikit pun bahasa khas remaja, bahkan tidak jarang sedikit banyak orang yang menganggap bahwa remaja ini sedang bermain-main dan ada juga yang beranggapan bahwa bahasa gaul tersebut dapat merusak etika serta tatanan bahasa Indonesia yang baik dan benar.

Bahasa remaja memang selalu berubah, pada dasarnya sesuai dengan remaja itu sendiri yang memang masih labil, masih belum mapan dan juga masih belum punya pendirian. Perubahan tersebut memang tidak dapat diramalkan oleh kalangan remaja itu sendiri. Kalau kita bertanya tentang bahasa apa yang dipakai oleh remaja tersebut, mereka pastinya menjawab menurut kemauan mereka masing-masing yang mereka inginkan. Misalnya Ia mengatakan bahwa bahasa yang ia gunakan adalah bahasa anak jaman sekarang, ada juga yang mengatakan bahasa rahasia, ataupun bahasa untuk menjalin keakraban, sebenarnya tidak lain adalah bahasa gaul sendiri.

Penggunaan bahasa gaul di kalangan remaja juga merambat sampai ke dunia maya seperti media sosial yang paling banyak penggunanya terutama media sosial instagram. Sebagai salah satu media yang paling banyak digunakan di antara media sosial lainnya dalam komunikasi secara virtual maupun tidak langsung.

Menurut Enterprise (dalam Listyorini, 2015: 18), menjelaskan bahwa bangsa Indonesia merupakan salah satu pengguna instagram terbesar dengan jumlah pengguna sekitar 17,6 juta orang. Peneliti tertarik untuk meneliti media sosial instagram apalagi sama-sama bisa kita amati kebanyakan dari para akun media sosial instagram yang selalu memperbarui statusnya kebanyakan 
didominasi oleh kalangan remaja yang menggunakan bahasa gaul sebagai media komunikasinya baik itu komunikasi antara teman seusianya ataupun antara seseorang yang usianya lebih tua darinya.

Bahasa gaul sebagai salah satu jenis atau ragam bahasa yang sering dipakai dikalangan remaja adalah suatu bahasa yang mempunyai keunikan yang menarik serta khas sehingga sangat cocok untuk diteliti dan dicermati dari segi jenis dan maknanya. Oleh sebab itu, peneliti tertarik untuk mengangkat masalah ini ke dalam bentuk karya tulis ilmiah yang berbentuk skripsi guna memperdalam pemahaman tentang penggunaan bahasa gaul remaja terutama dalam akun media sosial instagram.

\section{B. Landasan Teori}

\section{Pengertian Bahasa}

Bahasa adalah suatu keahlian yang dimiliki oleh makhluk hidup yang bernama manusia untuk berkomunikasi dengan manusia lainnya menggunakan tanda, misalnya dengan menggunakan kata dan gerakan. Dalam kehidupan sehari-hari, baik kehidupan nyata ataupun maya, kita tentu melafalkan suatu bahasa saat berbicara, baik itu bahasa Indonesia, bahasa daerah atau bahasa asing.

Kata "bahasa" itu sendiri berasal dari bahasa Sanskerta, yaitu dari kata bhāṣā. Definisi bahasa secara umum bisa juga diartikan sebagai sarana untuk berinteraksi dan berkomunikasi suatu masyarakat, dalam artian sebuah sarana atau media untuk menyampaikan pikiran, menuangkan gagasan, mengimplementasikan konsep atau mengungkapkan suatu perasaan. Sedangkan kajian ilmiah yang membahas tentang bahasa disebut sebagai ilmu linguistik.

Secara sederhana, bahasa juga bisa diartikan sebagai media untuk mengapresiasikan sesuatu yang terpendam di dalam hati seseorang. Namun, jika kita pahami lebih jauh bahasa hanya merupakan sarana untuk berinteraksi atau media untuk berkomunikasi, dalam artian media untuk 
menyampaikan pikiran, menuangkan gagasan, mengimplementasikan konsep atau mengungkapkan perasaan seseorang. Dalam studi kasus yang ranahnya sosiolinguistik, bahasa didefinisikan sebagai suatu sistem lambang yang berupa bunyi, juga mempunyai sifat arbitrer dan unik, selalu produktif, dinamis, universal, beragam serta bersifat manusiawi.

\section{Variasi Bahasa}

Variasi Bahasa muncul dikarenakan anggota masyarakat penutur bahasa itu sangatberagamdanbahasaitusendiridigunakanuntukkebutuhanyang sangat beragam- ragam pula. Dalam suatu masyarakat tertentu terdapatsejenis kesepakatan untuk menandai segala perbedaan yang terdapat pada dua macam variasi bahasa yang dibedakan berdasarkan status pemakaianya, yaitu:

1. Variasi bahasa tinggi, biasanya dipakai dalam kondisi formal, contohnya pidato kenegaraan, dan buku pelajaran.

2. Variasi bahasa rendah, biasanya digunakan dirumah, di pasar, di warung, serta tempat umum lainnya.

Ragam bahasa merupakan variasi bahasa yang digunakan dalam situasi keadaan atau keperluan tertentu. Untuk situasi formal biasanya menggunakan ragam baku atau ragam standar, sedangkan untuk situasi tidak formal biasanya menggunakan ragam tidak baku. Adapun dari media yang digunakan dapat diketahui perbedaannya menjadi ragam bahasa lisan maupun bahasa tulis.

UntukkeperluanpemakaiandibedakanmenjadiragambahasaIlmiah,jur nalistik, hukum,meliter,danbahasasastra(LinguistikUmum,AbdulChear, 1994).

\section{Bahasa Gaul}

Pergaulan dikalangan remaja mengenal apa yang dinamakan dengan budaya kerabat sebaya. Kelompok remaja yang usianya sama itu umumnya 
memiliki nilai serta karakteristik budaya yang juga berbeda atau bahkan dapat bertentangan dengan budaya para masyarakat dewasa. Mereka merasakan bahwasanya semua orang dewasa terlalu banyak mengatur dan juga mengawasi serta mengontrol hidup mereka, sementara mereka merasa bukan anak kecil lagi. Maka, upaya yang dilakukan oleh kaum remaja untuk memisahkan diri dari budaya sekelompok orang dewasa, mereka membuat budaya yang baru, budaya yang khas dikalangan remaja (Alatas, 2006: 59). Budaya khas remaja ini kemudian menciptakan lahirnya sebuah bahasa yang biasa dipakai oleh kalangan remaja untuk berkomunikasi serta berinteraksi dengan kaum sesama remaja. Bahasa tersebut kemudian dinamakan bahasa

gaul, sesuai dengan definisi awalnya yakni bahasa yang dipakai untuk menjalin pertemanan dan persahabatan di tengah masyarakat (KBBI, 2007

Bahasa gaul merupakan bahasa yang berasal dari bahasa prokem serta telah mengalami banyak sekali perkembangan dan perubahan. Istilah ini mulai lahir pada sekitar akhir tahun 1980-an. Kata 'prokem' itu sendiri berasal dari istilah kaum pencoleng yang biasanya untuk menyebut kata preman. Menurut Sumarsono dan Paina, 2004: 154, mengungkapkan bahwa istilah prokem tersebut kemudian dipakaiuntuk menyebut sebuah bahasa yang digunakan kaum pencoleng atau kalangan para preman untuk berkomunikasi serta berinteraksi dengan sesama kaumnya sebagai bahasa rahasia.

Pengguna bahasa gaul umumnya adalah sekelompok kaum remaja dan kaum artis dan selebritis. Biasanya bahasa gaul ini dipakai para kalangan remaja pada kondisi santai tidak resmi atau. Bahasa gaul seringkali digunakan pada tayangan-tayangan di televisi, majalah-majalah tabloid remaja serta sosial media.

\section{Gejala Bahasa}

Menurut Badudu, 1985:57, Gejala bahasa merupakan suatu peristiwa yang mengkaji tentang bentukan-bentukan sebuah kata atau kalimat dengan serangkaian proses pembentukannya. Beberapa gejala bahasa yang ditemukan dalam bahasa gaul pada penelitian sebelumnya berupa penghilangan fonem 
(aferesis, apokop, sinkop), proses penambahan sebuah fonem (protesis, efentesis, paragog), gejala adaptasi, monoftongisasi, akronim, dan singkatan.

\section{Kreativitas Linguistik}

Perbincangan mengenai sebuah bahasa tidak akan pernah ada habisnya. Berbagai macam bentuk hipotesis telah banyak dibuktikan sehingga muncul berbagai kajian yang membahas tentang bahasa. Namun, pertanyaan-pertanyaan hipotesis selanjutnya tiba-tiba lahir untuk menjadi bahan kajian para pemerhati serta peneliti bahasa. sehubungan dengan topik ini, ada sejumlah pertanyaan yang layak diapresiasi serta mendapat perhatian, di antaranya (1) adakah hubungan keterkaitan antara suatu bahasa dengan sebuah proses kreativitas, (2) apakah sebuah kreativitas dapat lahir tanpa adanya suatu bahasa, serta (3) apakah kegiatan berbahasa juga merupakan kegiatan dari sebuah kreativitas.

\section{Metode Penelitian}

Metode merupakan aspek terpenting dalam sebuah penelitian.. Menurut Sugiyono (2016: 6) metode penelitian merupakan suatu cara ilmiah yang digunakan untuk mendapatkan suatu data yang valid yang bertujuan dapat dibuktikan, ditemukan, dikembangkan, serta berisi pengetahuan sehingga dapat dimanfaatkan untuk memahami, memecahkan dan mengantisipasi sebuah masalah pada bidang pendidikan. Metode penelitian yang digunakan dalam penelitian skripsi ini adalah metode penelitian deskriptif kualitatif dengan tehnik kualitatif fenomenologis. Penelitian dengan metode deskriptif kualitatif yang bertujuan untuk mendeskripsikan situasi, proses atau gejala-gejala tertentu yang diamati. Bungin, 2007: 68 memaparkan, penelitian yang menggunakan metode kualitatif ini bertujuan untuk meringkas, menggambarkan, berbagai kondisi serta suatu fenomena realitas sosial yang ada pada masyarakat yang menjadi kajian penelitian dan berupaya menarik realita itu ke permukaan sebagai suatu tanda, karakter, ciri, model, atau gambaran tentang kondisi serta suatu fenomena tertentu.

Penelitian kualitatif ini mempunyai pengaturan yang alami sebagai sumber data yang diperoleh secara langsung, dan peneliti sebagai instrumen kunci. 
Penelitian kualitatif deskriptif ini biasanya menekankan pada proses observatif partisipatif, wawancara secara mendalam serta dokumentasi. Maka dalam sebuah penelitian yang dilakukan ini, peneliti lebih menekankan pada sebuah proses observasi dan wawancara secara mendalam guna menggali data bagi proses suatu validitas penelitian yang telah dilakukan ini, tetapi masih tetap menggunakan metode dokumentasi.

\section{Hasil dan Pembahasan}

Dalam bab ini akan diuraikan hasil penelitian, pembahasan dari masalah yang dikaji, serta analisis data dideskripsikan berdasarkan masalah dan tujuan penelitian yang telah dirumuskan. Hasil penelitian menunjukkan bahwa fenomena bahasa gaul sebagai kreativitas lingusistik sering digunakan oleh para generasi milenial dalam pergaulannya sehari-hari sering menggunakan bahasa gaul pada media sosial yakni instagram. Walaupun mereka sendiri terkadang tidak menyadari ataupun mengetahui bahasa yang mereka gunakan itu adalah bahasa gaul. Penggunaan bahasa gaul oleh generasi milenial melalui media sosial instagram dapat dideskripsikan sebagai berikut.

\section{Karakteristik bahasa gaul dalam media sosial instagram pada era milenial}

Sekilas, bahasa ini memiliki pola manasuka, tetapi kemampuan bahasa gaul ini menyebar ke kata lainnya, yang disebut difusi leksikal (Holmes, 1992:222 dan Wardhaugh, 2006:212), membuatnya menarik untuk diteliti. Dengan kata lain, kaidah perubahan yang terjadi pada bahasa gaul akan berdifusi dan menyebar ke kata-kata yang lain, sehingga bahasa gaul ini semakin banyak, misalnya kata awal bahasa gaul ini hanya serius "ciyus", semangat "cemungud", selalu "celalu" yang dalam perkembangannya menyebar ke kata-kata lain seperti suka "cuka", sungguh "cungguh", blokir "blocir". Gejala bahasa tersebut mengindikasikan adanya kaidah bahasa yang digunakan di dalamnya.

Berdasarkan data yang ditemukan dalam media sosial instagram pada era milenial, banyak gejala bahasa yang terjadi pada kosakata bahasa gaul, 
seperti perubahan/ inovasi/ substitusi bunyi, split, dan merger (lihat Keraf, 1984). Dari analisis yang dilakukan, ditemukan juga beberapa kaidah yang ada dalam bahasa gaul ini yang dibagi menjadi 3, yaitu perubahan, split, dan merger, sebagai dijelaskan berikut ini.

\section{a. Perubahan/ Inovasi/ Substitusi Bunyi}

Kridalaksana, 2008:229 memaparkan bahwa Perubahan/ Inovasi/ Substitusi bunyi yang dimaksud disini dapat dikatakan merupakan proses atau hasil penggantian unsur bahasa oleh unsur lain dalam satuan yang lebih besar untuk memperoleh unsur-unsur yang berbeda atau untuk menjelaskan suatu struktur tertentu. Perubahan atau inovasi bunyi ini dibagi menjadi 2 yaitu inovasi primer dan inovasi sekunder (Keraf, 1984).

1. Inovasi Primer

Inovasi primer adalah perubahan bunyi atau bentuk yang mengakibatkan terciptanya kata baru (Kridalaksana, 2008:94) secara primer atau berkaidah utama dalam bahasa gaul ini. Dengan kata lain, kaidah perubahan ini sangat sering muncul atau digunakan pada pola kata-katanya. Inovasi primer ini memiliki syarat sedikitnya ada 5 data yang menggunakannya.

Inovasi ai> uy

Perubahan/ inovasi bunyi /ai/ dalam Bahasa Indonesia menjadi bunyi /uy/ dalam bahasa gaul.

Contohnya bisa kita lihat pada postingan akun yang bernama wirda_mansur Kata santai menjadi santuy 
wirda_mansur Tanpa social distancing pun, memang sudah ada jarak di antara kita

Sebelum ada lockdown, hatiku memang sudah

tertutup untukmu

LatePost, aslinya mah lagi rebahan santuy :v

Siap siap besok \#KawalCoronaDenganSholawat day

Penambahan bunyi /-i/ di akhir kata.

Contohnya bisa kita lihat pada postingan akun yang bernama bintangemon

Kata begini menjadi beginiiii

457.792 suka

bintangemon Kenapa nggak dari dulu si, galon ada

handgripnya beginiiii $\Theta$ kan kasian mamah kalo gua

lagi ga di rumah.

Juga dapat kita temukan pada postingan instagram dengan nama akun nadia.abdurrahman

Kata dedek aik menjadi dedekaaaaaiiiiikkkk

Q. Disukai oleh kafamaula_15 dan 8.356

nadia.abdurrahman dedekaaaaiiiiiikkkkk ?

Lihat semua 9 komentar

Penambahan bunyi /-u/ di tengah kata dan bunyi /-a/ akhir kata.

Contohnya bisa kita lihat pada postingan akun yang bernama shofiaaaaaa

Kata bahagia menjadi buuahagiaaaaaaa 


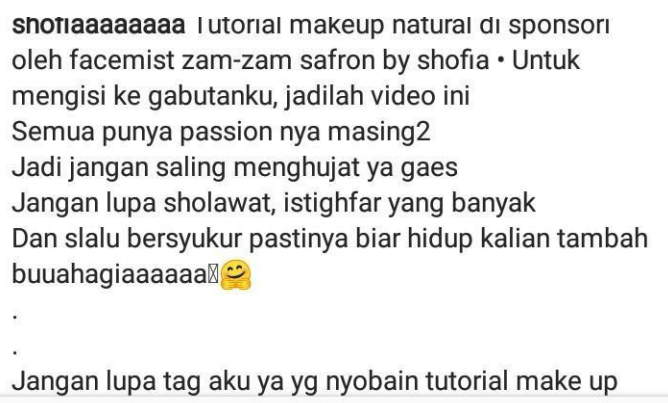

Inovasi $\mathrm{k}>\mathrm{y}$

Perubahan/ inovasi bunyi /k/ dalam Bahasa Indonesia menjadi bunyi /y/ dalam bahasa gaul

Contohnya bisa kita lihat pada postingan akun yang bernama ninikwafiroh

Kata oke menjadi oye

\begin{abstract}
inikwafiroh Yakinlah ini pose yang mikirnya super ama, pengen sok kayak model, plus photographernya @teddy_wardhana24 yang cerewetnya tingkat langit jiru di angkasa, ditambah tempatnya di @osingdelesresto yang oye bingit...... jadilah fotonya sok begaya gigit cherry, padahal biasanya yo angsung diemplok, gak sok genit gigit-gigit

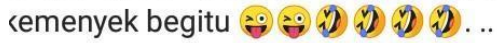

Selamat hari Jumat ya, tetep yakin Gusti Allah Maha 3aik, jadi jangan berhenti meminta
\end{abstract}

Inovasi singkatan yang diambil dari bahasa asing

naila_mafazah Jika suatu saat nanti kau sudah menemukan seseorang yang sehati dan satu tujuan. Perlahan kau akan paham, bahwa patah hatimu dulu bukan hanya untuk disesali, namun juga untuk disyukuri.

Karena, Cinta bisa berwujud menjadi siapapun selain dia.

\#ikutmirrorchallange

Btw foto di cermin terinspirasi dari @shireeenz ..
Contohnya bisa kita lihat pada postingan akun yang bernama nailamafaza

Kata by the way menjadi btw

Juga dapat ditemukan pada akun instagram mahrusaly.jr

Kata oh my god menjadi omg

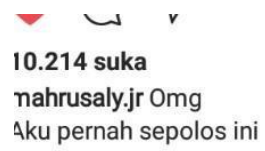


Inovasi s > c

Perubahan/ inovasi bunyi /s/ dalam Bahasa Indonesia menjadi bunyi /c/ dalam bahasa gaul.

\begin{tabular}{|l|l|}
\hline Bahasa Indonesia & Bahasa Gaul \\
\hline Ah Masa & Amaca \\
\hline Semangat & Cemungud \\
\hline Sekali & Cekali \\
\hline Pusing & Pucing \\
\hline
\end{tabular}

Inovasi $\mathrm{r}>\mathrm{y}$

Perubahan/ inovasi bunyi /r/ dalam Bahasa Indonesia menjadi bunyi /y/ dalam bahasa gaul

\begin{tabular}{|l|l|}
\hline Bahasa Indonesia & Bahasa Gaul \\
\hline Berat & Beyat \\
\hline Terus & Teyus \\
\hline Kirim & Kiyim \\
\hline Merem & Meyem \\
\hline Rahasia & Lahasia \\
\hline
\end{tabular}

Penambahan /-h/ di akhir kata

Contohnya bisa kita lihat pada postingan akun yang bernama raffinagita1717

Kata bebi menjadi beibiiiiihhhh

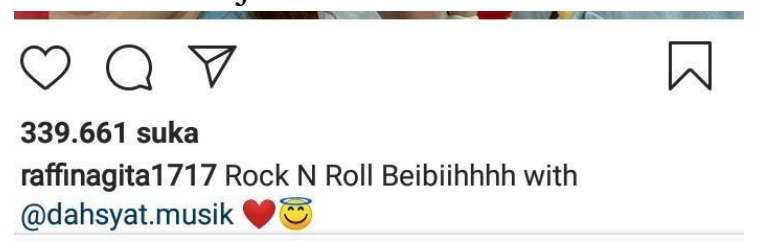

Juga dapat kita temukan pada psotingan akun instagramnya safriei_b

Kata biasa menjada byasah 


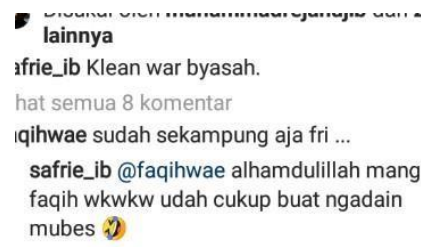

\begin{tabular}{|l|l|}
\hline $\begin{array}{l}\text { Bahasa } \\
\text { Indonesia }\end{array}$ & Bahasa Gaul \\
\hline Aku & Akooh \\
\hline Cinta & Cintah \\
\hline Gitu & Getoh \\
\hline Hello & Helloh \\
\hline Sama Siapa & Macapah \\
\hline Demi Apa & Miapah \\
\hline
\end{tabular}

Inovasi sekunder

Inovasi sekunder adalah perubahan bunyi atau bentuk yang mengakibatkan terciptanya kata baru (kridalaksana, 2008:94) secara sekunder atau berkaidah sekunder dalam bahasa gaul ini. Dengan kata lain, jika kaidah primer itu sering muncul, kaidah perubahan ini kadangkala saja munculnya atau secara sporadis/ tiba-tiba. Inovasi ini hanya memiliki data pendukung kurang dari 5. Kaidah perubahan sekunder tersebut antara lain:

Inovasi $r>1$

Perubahan/ inovasi bunyi /r/ dalam Bahasa Indonesia menjadi bunyi /1/ dalam bahasa gaul

\begin{tabular}{|l|l|}
\hline Bahasa Indonesia & Bahasa Gaul \\
\hline Beneran & Benelan \\
\hline Rahasia & Lahasia \\
\hline
\end{tabular}

Inovasi $\mathrm{t}>\mathrm{d}$

Perubahan/ inovasi bunyi /t/ dalam bahasa indonesia menjadi bunyi /d/ dalam bahasa gaul

\section{Bahasa Indonesia}

Bahasa Gaul 


\begin{tabular}{|l|l|}
\hline Banget & Beud \\
\hline Semangat & Cemungud \\
\hline
\end{tabular}

Inovasi $\mathrm{k}>\mathrm{c}$

Perubahan/ inovasi bunyi /k/ dalam Bahasa Indonesia menjadi bunyi /c/ dalam bahasa gaul

\begin{tabular}{|l|l|}
\hline Bahasa Indonesia & Bahasa Gaul \\
\hline Blokir & Blocir \\
\hline Kabel & Chabel \\
\hline
\end{tabular}

$\mathrm{k}->\varnothing$

Pelepasan bunyi /k/ di awal kata bahasa indonesia dalam gaul

\begin{tabular}{|l|l|}
\hline Bahasa Indonesia & Bahasa Gaul \\
\hline Kangen Kamu & Angenamu \\
\hline
\end{tabular}

$-k->\varnothing$

Pelepasan bunyi /k/ di tengah kata Bahasa Indonesia dalam bahasa gaul

\begin{tabular}{|l|l|}
\hline Bahasa Indonesia & Bahasa Gaul \\
\hline Makasih & Maacih \\
\hline
\end{tabular}

Berdasarkan hasil analisis, perubahan bunyi bahasa gaul ini begitu bervariasi dan melibatkan beberapa proses perubahan sekaligus dalam satu bentuk bahasa. Hal ini sesuai dengan pendapat Wijana (2010:38) yang mengatakan bahwa perubahan bentuk bahasa gaul seperti ini terjadi secara simultan atau beberapa proses terjadi sekaligus. Hasil analisis juga menunjukkan bahwa bahasa gaul ini memiliki kaidah primer dan sekunder secara sistemik, sehingga dapat memproduksi kata-kata baru dengan mengikuti kaidah tersebut. Dengan kata lain, penelitian ini menunjukkan kemampuan difusi leksikal pada sistem kebahasaan bahasa gaul ini. 
Secara keseluruhan, kaidah perubahan dalam Bahasa Indonesia menjadi bahasa gaul tersebut terjadi pergeseran tempat artikulasi bunyi dari tengah ke depan dan pelesapan bunyi-bunyi yang berartikulasi di bagian belakang (dorso velar dan glotal), seperti perubahan bunyi 'l' ke 'w' (dental ke bilabial), 'k' ke 'c' (velar ke alveolar), 'r' ke 'l' (alveolar ke dental), ' $y$ ' ke 'n' (sentrodomal ke dental), pelesapan bunyi 'k', 'g', ' $y$ ', dan penghilangan bunyi getar. Selain itu, terjadi penyingkatan dua/ beberapa kata menjadi satu kata, pengimbuhan 'h' di akhir kata, dan penyisipan 'y' di tengah kata yang bertujuan untuk kemudahan pengucapan. Jadi, dapat disimpulkan bahwa sebagian besar kaidah yang digunakan dalam bahasa gaul ini mengikuti cara artikulasi anak usia 1- 4 tahun jika mengamati bunyi vokal dan konsonan yang digunakan (lih. Steinberg, dkk., 2001:3-6; Owens (2012:95-96)). Hal ini banyak dilatarbelakangi karena pengguna bahasa gaul ini ingin terlihat/ terdengar lucu seperti anak kecil atau manja sebagaimana disampaikan oleh Suprihatien (2016:77).

\section{Padanan kosakata bahasa gaul dengan bahasa Indonesia}

\section{a. Gawai}

Gawai merupakan kata Bahasa Indonesia yang baru serta baku untuk menyebut gadget. Gawai sendiri mempunyai arti perkakas atau alat. Karena benda-benda elektronik seperti laptop, tab, atau ponsel masih dikategorikan sebagai alat, maka gawai dianggap merupakan kata yang tepat untuk menggantikan gadget.

\section{b. Warganet}

Untuk kalian yang sering mengikuti akun-akun Instagram artisartis atau infotainment pasti sering mendengar istilah netizen, bukan? Ya, warganet adalah kosakata baru yang digunakan untuk mengganti istilah netizen.

\section{c. Saltik}

“Duh, saltik terus!” kira-kira kalimat seperti inilah yang mulai sekarang harus kalian terapkan kalau kalian melakukan typo. Jangan 
heran, saltik alias salah ketik adalah kosakata pengganti untuk typo dan sudah ada dalam kamus besar bahasa Indonesia.

\section{Proses pembentukan bahasa gaul}

Pola Pembentukan kata dalam bahasa gaul berdasarkan Plesetan Menurut Sibarani (2008:256-268) plesetan merupakan proses pembentukan kata dengan cara memplesetkan sebuah kata sehingga makna kata itu bertambah dari makna semula. Plesetan memiliki banyak fungsi kultur, diantaranya sebagai olok-olokan, sindiran, eufemisme, ungkapan rahasia dan sebagai lelucon atau hiburan dalam berkomunikasi. Menurut Baryadi (2003:27) plesetan merupakan tindak tutur yang menggelincirkan satuan lingual yang secara konvensional memiliki bentuk makna tertentu ke satuan lingual yang memiliki bentuk makna lain. Ada plesetan yang hanya mengubah bunyi suatu kata, tetapi ada juga plesetan yang mengubah atau menggelincirkan struktur kebahasaan yang lebih rumit.

Pola pembentukan kata berdasarkan pelesetan dapat dianalisis dengan melihat kata A yang semula bermakna B, lalu dipelesetkan menjadi bermakna C yang memiliki konotasi baru. Pola Pembentukan Berdasarkan Kata Baru ini awalnya digunakan kalangan preman untuk berkomunikasi satu sama lain secara rahasia. Penambahan bunyi atau huruf ditengah kata dilakukan dengan cara menyisipkan huruf (-ok) diantara konsonan dan vokal suku kedua. Saat ini varian prokem menajdi umum digunakan sebagai bentuk percakapan sehari -hari dalam pergaulan dilingkungan sosial bahkan dalam media-media populer seperti televisi, radio, dan sosial media. Remaja saat ini pun merancang katakata baru dengan beberapa cara. Salah satunya dengan penambahan sisipan (ok) ditengah kata yang sudah disusutkan (Sumarsono 2013:154) contohnya kata bapak menjadi bokap, gila menjadi gokil.

\section{Dampak positif dan negatif bahasa gaul dalam media sosial instagram pada era milenial}

a. Eksistensi Bahasa Indonesia Terancam Terpinggirkan Oleh Bahasa Gaul 
Berbahasa sangat erat kaitannya dengan budaya sebuah generasi. Kalau generasi negeri ini kian tenggelam dalam pudarnya bahasa Indonesia yang lebih dalam, mungkin bahasa Indonesia akan semakin sempoyongan dalam memanggul bebannya sebagai bahasa nasional dan identitas bangsa.

Dalam kondisi demikian, diperlukan pembinaan dan pemupukan sejak dini kepada generasi muda agar mereka tidak mengikuti pembusukan itu. Pengaruh arus globalisasi dalam identitas bangsa tercermin pada perilaku masyarakat yang mulai meninggalkan bahasa Indonesia dan terbiasa menggunakan bahasa gaul

Saat ini jelas di masyarakat sudah banyak adanya penggunaan bahasa gaul dan hal ini diperparah lagi dengan generasi muda Indonesia juga tidak terlepas dari pemakaian bahasa gaul.

b. Menjadi Salah Satu Penyebab Punahnya Bahasa Indonesia

Penggunaan bahasa gaul yang semakin marak di kalangan remaja merupakan sinyal ancaman yang sangat serius terhadap bahasa Indonesia dan pertanda semakin buruknya kemampuan berbahasa generasi muda zaman sekarang. Sehingga tidak dapat dipungkiri suatu saat bahasa Indonesia bisa hilang karena tergeser oleh bahasa gaul di masa yang akan datang.

c. Mengganggu Pemahaman Bahasa Bagi Orang Lain

Bahasa gaul dapat mengganggu siapapun yang membaca dan mendengar kata-kata yang termaksud di dalamnya. Karena, tidak semua orang mengerti akan maksud dari kata-kata gaul tersebut. Terlebih lagi dalam bentuk tulisan, sangat memusingkan dan memerlukan waktu yang lebih banyak untuk memahaminya.

d. Menyulitkan Pemakaian Bahasa Indonesia

Penggunaan bahasa gaul dapat mempersulit penggunaan bahasa Indonesia dengan baik dan benar. Padahal di sekolah atau di tempat kerja, kita diharuskan untuk selalu menggunakan bahasa Indonesia yang baik dan benar. 
Tidak mungkin jika pekerjaan rumah, ulangan atau tugas sekolah dikerjakan dengan menggunakan bahasa gaul. Karena, bahasa gaul tidak masuk ke dalam tatanan bahasa akademis. Begitu juga di kantor, laporan yang kita buat tidak diperkenankan menggunakan bahasa gaul. Jadi, ketika situasi kita dalam situasi yang formal jangan menggunakan bahasa gaul sebagai komunikasi.

e. Menurunnya Derajat Bahasa Indonesia

Karena bahasa gaul yang begitu mudah untuk digunakan berkomunikasi dan hanya orang tertentu yang mengerti arti dari bahasa gaul, maka remaja lebih memilih untuk menggunakan bahasa gaul sebagai bahasa sehari-hari. Sehingga bahasa Indonesia semakin pudar bahkan dianggap kuno di mata remaja dan juga menyebabkan turunnya derajat bahasa indonesia.

\section{E. Kesimpulan}

Sekilasbahasa memiliki pola manasuka, tetapi kemampuan bahasa gaul ini menyebar ke kata lainnya, yang disebut difusi leksikal (Holmes, 1992:222 dan Wardhaugh, 2006:212), membuatnya menarik untuk diteliti. Dengan kata lain, kaidah perubahan yang terjadi pada bahasa gaul akan berdifusi dan menyebar ke kata-kata yang lain, sehingga bahasa gaul ini semakin banyak.

Adapun contoh padanan kosakata bahasa gaul ke dalam bahasa Indonesia yakni pada kata gawai. Gawai merupakan kata bahasa Indonesia yang baru serta baku untuk menyebut gadget. Gawai sendiri mempunyai arti perkakas atau alat. Karena benda-benda elektronik seperti laptop, tab, atau ponsel masih dikategorikan sebagai alat, maka gawai dianggap merupakan kata yang tepat untuk menggantikan gadget.

Pola pembentukan kata dalam bahasa gaul berdasarkan Plesetan Menurut Sibarani (2008:256-268) plesetan merupakan proses pembentukan kata dengan cara memplesetkan sebuah kata sehingga makna kata itu bertambah dari makna semula. Plesetan memiliki banyak fungsi kultur, diantaranya sebagai olok-olokan, sindiran, eufemisme, ungkapan rahasia 
dan sebagai lelucon atau hiburan dalam berkomunikasi. Menurut Baryadi (2003:27) plesetan merupakan tindak tutur yang menggelincirkan satuan lingual yang secara konvensional memiliki bentuk makna tertentu ke satuan lingual yang memiliki bentuk makna lain. Ada plesetan yang hanya mengubah bunyi suatu kata, tetapi ada juga plesetan yang mengubah atau menggelincirkan struktur kebahasaan yang lebih rumit.

Bahasa merupakan bagian dari kebudayaan dan bahasalah yang memungkinkan berkembangnya kebudayaan semakin pesat sebagaimana kita ketahui sekarang. Mengingat bahasa nasional atau bahasa kebangsaan di Indonesia adalah bahasa Indonesia sendiri, lahirnya berbagai ragam bahasa asing yang digunakan dalam jejaring sosial ini dapat memyebabkan bumerang. Karena dalam sisi negatifnya jelas akan merusak tatanan bahasa Indonesia. Yang perlu kita ketahui dampak positif dari digunakannya bahasa gaul ialah dapat menumbuhkan kreativitas pada kalangan remaja. Terlepas dari membingungkan atau tidaknya bahasa gaul ini, tidak ada salahnya kalau kita menikmati hasil karya dari tiap perubahan atau segala inovasi bahasa yang muncul. Namun, harus dipakai pada situasi yang tepat, kondisi yang sesuai, sarana media yang singkron dan komunikan dengan orang yang tepat juga. Pada mahasiswa yang juga calon guru, terlebih guru bahasa Indonesia. Bahasa gaul hendaknya dipahami sebagai salah satu ragam bahasa yang akan menambah kekayaan bahasa Indonesia. Namun, bukan berarti dengan adanya pemakluman seperti ini penguasaan dan kecintaan terhadap bahasa Indonesia menjadi rendah.

Kita memang sering berada pada situasi informal sehingga bisa sering menggunakan multibahasa. Tapi jangan sampai kita melupakan sama bahasa Indonesia yang hakikatnya baik dan benar. Sebagai anak muda kita mesti tetap menjaga bahasa Indonesia dengan cara sebagai berikut:

1. Memakai bahasa gaul tapi tetap perhatikan konteksnya

Kita memang tidak selalu menggunakan bahasa Indonesia yang baik dan benar, tapi juga harus sesuai dengan konteks. Jadi bisa saja kita berbahasa benar tapi tidak baik. "Jadi baik itu artinya sesuai konteks atau situasi bahasa itu dipakai. Dan bahasa itu dapat dikatakan benar kalau 
sudah sesuai dengan kaidah tata Bahasa Indonesia," kata Dora Amalia, selaku Kepala Badan Pengembangan Badan Bahasa.

Nukman Luthfie, seorang pengamat tren media sosial mengatakan bahwa memakai bahasa gaul boleh itu boleh-boleh saja. Tapi harus diingat, bahasa gaul itu termasuk bahasa kasual. Tidak boleh dipakai pada karya ilmiah, untuk mengirim email, serta digunakan pada hal-hal yang bersifat formal.

2. Tetap memperhatikan tata bahasa ketika menggunakan campur kode

Terlalu sering memakai bahasa Indonesia dicampur bahasa Inggris, kita jadi terbiasa juga mencampur-adukkan gramatikalnya. Kalau mau menggunakan kata-kata bahasa Inggris jangan memakai gramatikalnya bahasa Indonesia. Misalnya, kita sering menyebut player game online. Padahal, yang bener adalah online game player

3. Kuasai dengan benar bahasa Indonesia

Kita pasti akan keren apabila fasih berbahasa gaul tapi tidak terbatabata ketika harus berbicara menggunakan bahasa Indonesia dalam situasi formal, bisa cepat memahami saat membaca artikel dengan katakata Indonesia yang jarang dipakai sehari-hari dan saat menulis setidaknya tahu kapan imbuhan di- harus dipisah dan harus disambung.

\section{Daftar Pustaka}

Afifuddin, Beni \& Ahmad Saebani. 2014. Metodologi Penelitian Kualitatif. Bandung: Pustaka Setia.

Djajasudarma, Fatimah. 2012. Metode Lingustik: Ancangan Metode Penelitia Dan Kajian. Bandung: PT Refika Aditima.

Mahsun, 2014. Metode Penelitian Bahasa. jakarta: Rajawali Pers.

Moleong, L. 2017. Metodologi Penelitian Kualitatif. Bandung: PT Remaja Rosdakarya.

Keraf, Gorys. 1984. Linguistik Bandingan Historis. Jakarta: PT. Gramedia.

Kridalaksana, Harimurti. 2016. Kamus Linguistik. Jakarta: PT Gramedia Pustaka Utama. 
Sumarsono. 2012. Sosiolinguistik. Yogyakarta: Pustaka Pelajar

Suprihatien. 2016. "Fenomena Penggunaan Bahasa Kekinian di Kalangan

Mahasiswa”.Jurnal INOVASI Volume XVIII Nomor 2.

Saussure, F. 1965. Cours in general Linguistics. Terjemahan Wade Baskin.

New York: McGraw-Hill.

https://www.google.com/search?client=firefox-b-d\&q=pengertian+bahasadiakses pada tanggal 20 juli 2020

http://p4tkbahasa.kemdikbud.go.id/2019/10/21/padanan-kosakata-

daribahasaasing-ke-bahasa-indonesia/ diakses pada tanggal 6 mei 2020 